\title{
Optimization of Machining Parameters of Surface Roughness And MRR During Milling of OHNS using Vertical Milling Machine
}

\author{
M.Prakash \\ PG Scholar, \\ Depatment of mechanical Engineering \\ Chadalawada Ramanamma Engineering College \\ Tirupati
}

\author{
Dr Lakshmi Tulasi Chavali \\ Associate Professor \\ Department of Mechanical Engineering \\ Chadalawada Ramanamma Engineering College \\ Tirupati
}

\begin{abstract}
Manufacturing technology has been a driving force behind modern economies since the Industrial Revolution. Although manufacturing techniques have become more sophisticated in the improvement of industrial products and processes. The Quality is designed, not manufactured in to the product. The key element for achieving high quality and low cost is parameter design. Through parameter design, levels of process factors are determined, product's functional characteristics are optimized and the effect of noise is minimized.

The objective of the present work is to apply Taguchi method to investigate the effects of milling parameters such as cutting speed, depth of cut and feed rate on surface roughness,MRR.The present work carrying on vertical milling machine and Tungsten Carbide is selected as cutting tool to machine the OHNS Steel.
\end{abstract}

Keywords-ANOVA, Material Removal Rate,Surface Roughness.

\section{INTRODUCTION}

Milling is the process of removing metal by feeding the work past a rotating multipoint cutter. In milling operation, the rate of metal removal is rapid as the cutter rotates at a high speed and has many cutting edges. Thus, the jobs are machined at faster rate than with single point tools and the surface finish is also better due to multi cutting edges.

Milling machine is one of the most important machine tools in a tool room as nearly all the operations can be performed on it with high accuracy. Milling machine augments the work of a lathe and can produce the plain and curved surfaces and helical grooves etc. The milling machine may be so arranged that the several cutters are mounted on the arbor at the same time, thus increasing the metal removal rate and allowing several surfaces to be machined at the same time. The action of milling cutter is vastly different from that of a drill or lathe tool. In milling operation, the cutting edge of the cutter is kept continuously in contact with the material being cut. The cut picks up gradually only.

Milling machines can be used for machining flat surfaces, contoured surfaces, complex and irregular areas, surfaces of revolution, slotting, external and internal threads, gear cutting and helical surfaces of various cross sections etc. The versatility and accuracy of the milling process causes is to be widely used in modern machining manufacturing.

Normally, the milling operation creates plane surfaces. Other geometries can also be created by milling machine. Milling operation is considered an interrupted cutting operation. Teeth of milling cutter enter and exit the work during each revolution. This interrupted cutting action subjects the teeth to a cycle of impact force and thermal shock on every rotation. The tool material and cutter geometry must be designed to bear the above stated conditions.

The variety being demanded in view of the varying tastes of the consumer calls for a very small batch sizes. Small batch sizes will not be able to take advantage of the mass production techniques such as special purpose machines or transfer lines.

\section{LITERATURE SURVEY}

This work reviews in details the literature for a better understanding of the problem discussed in this area.

S.KANNAN,N.BASKAR ,B.SURESHKUMAR[3] parametric optimization of machining parameters in Face milling process using RSM\&GA and particle swarm optimization with experimental verification. In this paper they have conducted experimental work on the vertical milling machine by using TUNGSTEN CARBIDE tool cutter and COPPER material was machined by milling process. They considered speed, feed and depth of cut as input parameters for finding material removal rate, surface roughness by using RSM \& GA they analyzed the effect of process parameters on MRR, Surface roughness, 2012.

PRAJAPATI et al. [4] have optimized the machining parameters for SR and MRR in CNC milling. SS 316 (austenite steel) work material of $\varnothing 45 \mathrm{~mm}$ and length $35 \mathrm{~mm}$ was used in turning in dry environment conditions. In this study, the effect and optimization of machining parameters (cutting speed, feed rate and depth of cut) on SR and MRR is investigated. An L27 orthogonal array, analysis of variance (ANOVA) ) and grey relation analysis is used, 2013.

BAYRAMOGLU AND OZCELIK [4] have modelled surface roughness in high speed flat end milling of steel including total tool operating time along with other machining variables such as spindle speed, feed rate, depth of cut and step over CHANG AND LU [6] have present fed the optimization of cutting parameters for side milling of medium carbon steel with multiple roughness characteristics, viz., feeding direction roughness, axial direction roughness and waviness, using grey relational Taguchi approach. Cutting aluminium alloys is a major manufacturing process in the automotive industries and the manufacturing of mould and die components. Milling with an end mill is one of the important 
machining processes for making profiles, slots, engraving, surface contouring, and pockets in precision molds and dies. The machining process is used in both roughing and finishing operations. Thus, the forming process; planning machining, milling, or milling the surface of the piece may cause loss of material. Such problems may be caused by several factors such as material, cutting speed, feed rate, cutting depth, and also the workers who have no expertise. The researcher, therefore, was interested in investigating any proper condition in $\mathrm{Al}$ 7075-T6 milling processes to benefit automotive industries and the manufacturing of mould and die components industries and to reduce time and cost for the better quality product. In addition, the research may be useful for any future research on the similar topic.

BAJIC et al. [2] performed the machining process for optimized the parameters for SR in face milling. Test sampleids made of carbon steel St 52-3 with dimensions 230x100x100 $\mathrm{mm}$ were used in experiments. The parameters cutting speed, depth of cut and feed on machined surface roughness in face milling process have been examined. The results of the performed research show that both feed and cutting speed influence on surface roughness but the feed is the most influential factor.

ANDSHAOO et al. [1] had given the outline of the soft material milling parameters in their study on optimization of CNC milling of UNS C34000 medium- leaded brass with multiple-surface roughness characteristics. A single-response study provided base in determining the parameters that were studied. The case studies conducted at the laboratory have prompted for the real-time studies and to find the solution for the manufacturing firms around the place.

CHOCKALINGAM et al.[8] studied the effect of different coolant conditions on milling of AISI 304 stainless steel.Cooling methods used in this investigation were flooding of synthetic oil, water-based emulsion, and compressed cold air. Cutting forces and the surface roughness were studied and tool flank wears observed. In this study, the comparison between different coolants effect to the milling of AISI 304 stainless steel is done.

CHANDRASEKARAN et al. [5] studied the machine ability of AISI 410 on CNC milling for SR using taguchi method. The effect and optimization of machining parameters on SR is investigated. L27 Orthogonal array, analysis of variance (ANOVA) is used in this investigation. The experiment was conducted on Fanuc CNC milling machine. Work material of $\varnothing 32 \mathrm{~mm}$ and length $60 \mathrm{~mm}$ was used.

JOSHI et al.[10] investigated the SR response on CNC milling by Taguchi technique. Analysis of variance (ANOVA) was used in this investigation. The material used for the experiment is $(100 \times 34 \times 20 \mathrm{~mm}) 5$ blocks of aluminium cast heat-treatable alloy. The output characteristic, surface finish is analysed by software Minitab 15 and ANOVA is formed, which shows the percentage contribution of each influencing factor on surface roughness.

\section{MATERIALS AND METHOD}

\section{i. Work Piece Material}

The work piece material used in this work was OHNS steel of length $25 \times 25 \times 100$.The work piece material is shown in fig below.

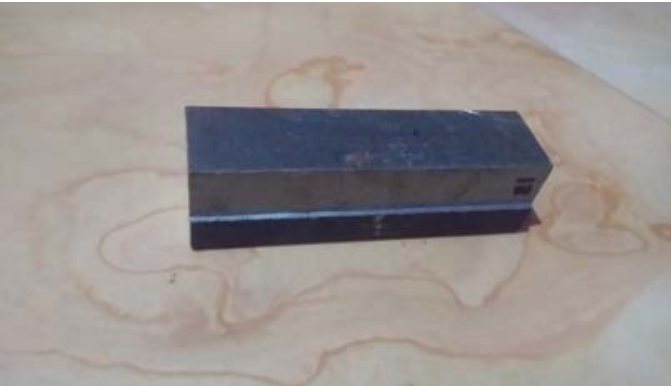

Fig 1 :OHNS Steel

TABLE 1.CHEMICAL COMPOSITION OF OHNS STEEL
\begin{tabular}{|c|c|c|c|c|c|}
\hline $\mathrm{C}$ & $\mathrm{Mn}$ & $\mathrm{Cr}$ & $\mathrm{T}$ & $\mathrm{Ni}$ & $\mathrm{Fe}$ \\
\hline $0.9-1.3$ & 1 & 0.5 & $0.4-0.8$ & 0.5 & remaining \\
\hline
\end{tabular}

\section{Tungsten Carbide Tool}

The main use of Tungsten Carbide continues to be in the manufacture of various cutting tools: drills, taps, milling cutters, tool bits, gear cutters, saw blades, planer and jointer blades, router bits, etc., although usage for punches and dies is increasing.

Tungsten Carbide also found a market in fine hand tools where their relatively good toughness at high hardness, coupled with high abrasion resistance, made them suitable for low speed applications requiring a durable keen (sharp) edge, such as files, chisels, hand plane blades, and damascus kitchen knives and pocket knives.

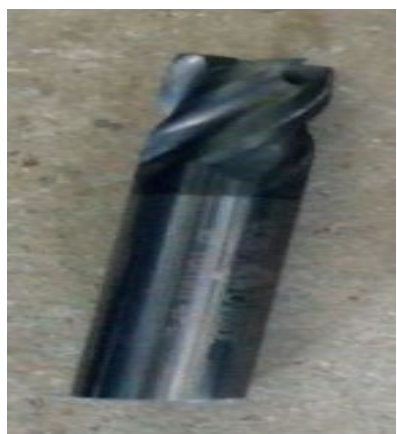

Fig 2 : Tungsten Carbide Tool

IV. EXPERIMENTAL DESIGN

In the present work L16 Taguchi orthogonal design has been used in order to study the effect of three process parameters (Depth of cut, Feed rate and Spindle speed) and the maching operations is carried on a vertical milling machine and the type of milling used in this work is end milling and ohns steel is used as a cutting tool and surface roughness, material removal rate is found out.surface roughness is measured in each run by surface Roughness Measuring instrument and material removal rate by using initial weight and final weight and time.

Process Parameters: The machining parameters are depending on the parameters such as speed, feed and depth of cut. The Table 2 shows the range and levels of machining parameters considered for experimental work.

TABLE 2.Ranges and levels of parameters

\begin{tabular}{|c|c|c|c|c|c|}
\hline \multirow{2}{*}{ Factors } & \multirow{2}{*}{ Unit } & \multicolumn{4}{|c|}{ Levels } \\
\cline { 3 - 6 } & & Level 1 & Level 2 & Level 3 & Level 4 \\
\hline Speed & Rpm & 246 & 386 & 427 & 669 \\
\hline Feed & Mm/min & 16 & 25 & 46 & 71 \\
\hline Doc & $\mathrm{mm}$ & 0.25 & 0.5 & 0.75 & 1 \\
\hline
\end{tabular}


Design of experiments :

Experimental work is carried out using taguchi:s L16 orthogonal array (OA) experimental design which consists of 16 combinations of speed,feed,depth of cut..taguchi's L16 orthogonal array is shown in table 3.

TABLE 3. $\mathrm{L}_{16}$ Orthogonal array

\begin{tabular}{|c|c|c|c|}
\hline SI.No & Cutting speed & Feed & Depth Of Cut \\
\hline 1 & 246 & 16 & 0.25 \\
\hline 2 & 246 & 25 & 0.5 \\
\hline 3 & 246 & 46 & 0.75 \\
\hline 4 & 246 & 71 & 1 \\
\hline 5 & 386 & 16 & 0.5 \\
\hline 6 & 386 & 25 & 0.25 \\
\hline 7 & 386 & 46 & 1 \\
\hline 8 & 386 & 71 & 0.75 \\
\hline 9 & 427 & 16 & 0.75 \\
\hline 10 & 427 & 25 & 1 \\
\hline 11 & 427 & 46 & 0.25 \\
\hline 12 & 427 & 71 & 0.5 \\
\hline 13 & 669 & 46 & 1 \\
\hline 14 & 669 & 25 & 0.75 \\
\hline 15 & 669 & 46 & 0.5 \\
\hline 16 & 669 & 71 & 0.25 \\
\hline
\end{tabular}

\section{RESULTS AND DISCUSSIONS}

TABLE 4. Experimental data and results for 3 parameters, Corresponding Ra and MRR for OHNS

\begin{tabular}{|c|c|c|c|c|c|}
\hline Level & Speed(S) & Feed(f) & Doc(d) & $\begin{array}{c}\text { Surface } \\
\text { Roughness }(\mu \mathrm{m})\end{array}$ & $\begin{array}{c}\text { Mrr } \\
\text { (gram/min) }\end{array}$ \\
\hline 1 & 246 & 16 & 0.25 & 2.55 & 0.511 \\
\hline 2 & 246 & 25 & 0.5 & 3.09 & 1.232 \\
\hline 3 & 246 & 46 & 0.75 & 3.07 & 3.898 \\
\hline 4 & 246 & 71 & 1 & 3.43 & 8.726 \\
\hline 5 & 386 & 16 & 0.5 & 2.79 & 0.717 \\
\hline 6 & 386 & 25 & 0.25 & 2.17 & 0.452 \\
\hline 7 & 386 & 46 & 1 & 2.04 & 4.364 \\
\hline 8 & 386 & 71 & 0.75 & 3.35 & 4.880 \\
\hline 9 & 427 & 16 & 0.75 & 2.11 & 1.253 \\
\hline 10 & 427 & 25 & 1 & 2.37 & 2.723 \\
\hline 11 & 427 & 46 & 0.25 & 2.23 & 1.212 \\
\hline 12 & 427 & 71 & 0.5 & 3.69 & 4.724 \\
\hline 13 & 669 & 16 & 1 & 2.35 & 2.208 \\
\hline 14 & 669 & 25 & 0.75 & 2.76 & 2.098 \\
\hline 15 & 669 & 46 & 0.5 & 3.27 & 2.398 \\
\hline 16 & 669 & 71 & 0.25 & 3.28 & 2.296 \\
\hline
\end{tabular}

Based on the orthogonal array of L16 doe the experiments were conducted to find the surface roughness,material removal rate.Experimatal results for 3 parameters corresponding Ra and Mrr is shown in the table 4.The main objevtive of this work is find the better operating conditions and also the influence of each parameter is evaluated.this can achieved in two methods.

\section{Annova Method}

2. Analysis using plotting by levels method

\section{ANNOVA METHOD}

Using Minitab 17 software, the experiments were carried out For the proposed method ANOVA (Analysis of variance) are calculated and tabulated.

The results of ANOVA for the responses surface roughness $(\mathrm{Ra})$, are shown the following Tables5 . surface roughness (Ra) versus Speed (s), Feed (f), and Depth of cut (d) is also allowed to determine the effect of any two cutting parameters where as other parameter is maintained constant throughout the design of experiments.

Table 5. Analysis of variance for surface roughness

\begin{tabular}{|c|c|c|c|c|c|c|}
\hline SOURCE & DF & SS & MS & F & P & C $\%$ \\
\hline SPEED & 3 & 0.6105 & 0.2035 & 6.46 & 0.026 & 14.12 \\
\hline FEED & 3 & 2.3627 & 0.7875 & 25.01 & 0.001 & 54.66 \\
\hline DOC & 3 & 1.1607 & 0.3869 & 12.51 & 0.006 & 26.85 \\
\hline ERROR & 6 & 0.1889 & 0.3149 & & & 4.37 \\
\hline TOTAL & 15 & 4.3229 & & & & 100.00 \\
\hline
\end{tabular}

The results of ANOVA for the responses material removal rate (MRR), are shown the following Tables 6. material removal rate (MRR) versus Speed (s), Feed (f), and Depth of cut (d) is also allowed to determine the effect of any two cutting parameters where as other parameter is maintained constant throughout the design of experiments.

Table 6. Analysis of variance for material removal rate

\begin{tabular}{|c|c|c|c|c|c|c|}
\hline SOURCE & DF & SS & MS & F & P & C \% \\
\hline SPEED & 3 & 4.210 & 1.4034 & 2.30 & 0.177 & 5.98 \\
\hline FEED & 3 & 38.358 & 12.7859 & 20.97 & 0.001 & 54.45 \\
\hline DOC & 3 & 24.224 & 8.0745 & 13.24 & 0.005 & 34.38 \\
\hline ERROR & 6 & 3.659 & 0.6098 & & & 5.19 \\
\hline TOTAL & 15 & 70.45 & & & & 100.00 \\
\hline
\end{tabular}

From Table 5 the \% contribution of values for speed (14.12\%), feed rate (54.66\%) and depth of cut (26.85\%). It is observed that the feed and speed have great influence on surface roughness.

From Table 6 the \% contribution of values for speed (4.21\%), feed rate (54.45\%) and depth of cut (34.38\%). It is observed that the Depth of cut and feed rate have great influence on material removal rate.

2. Analysis using plotting by levels method

In this method ,the average result for each level is calculated to plot the effect of influencial factors. The sum of data associated with each level in the orthogonal array column divided by number of test (data point) for that will provide 
the appropriate averages.the factors strengths are directly proportional to the slope of the graphs.

Table 7 . Response table for signal- to -noise ratio for Surface roughness (smaller is better) [Ra]

\begin{tabular}{|c|c|c|c|}
\hline Level & Speed(S) & Feed(f) & Depth of Cut(d) \\
\hline 1 & -9.595 & -7.737 & -8.036 \\
\hline 2 & -8.084 & -8.210 & -10.086 \\
\hline 3 & -8.072 & -8.298 & -8.887 \\
\hline 4 & -9.212 & -10.716 & -7.954 \\
\hline Delta(max-min) & 1.523 & 2.979 & 2.132 \\
\hline Rank & 3 & 1 & 2 \\
\hline
\end{tabular}

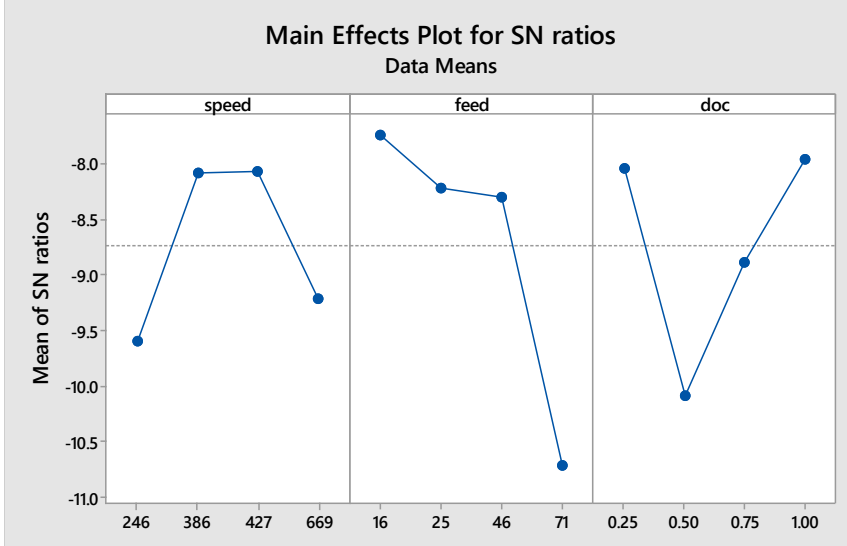

Signal-to-noise: Smaller is better

Figure 3: Main effect plot for the Ra

Main effect plot for SN ratios for the RA are shown in figure3 which sows the variation of surface roughness with the input parameters.

Table 8 . Response table for signal- to -noise ratio for material emoval rate (Larger is better)

\begin{tabular}{|c|c|c|c|}
\hline Level & Speed(S) & Feed(f) & Depth of Cut(d) \\
\hline 1 & 7.0341 & 0.0332 & -0.9568 \\
\hline 2 & 4.1812 & 2.5145 & 5.0044 \\
\hline 3 & 6.4564 & 8.4724 & 8.4799 \\
\hline 4 & 6.6551 & 13.3067 & 11.7993 \\
\hline Delta(max-min) & 2.8529 & 13.2735 & 12.750 \\
\hline Rank & 3 & 1 & 2 \\
\hline
\end{tabular}

Main effect plots for SN for Mrr are shown in figure 4 which shows the variation of MRR with the input parameters.

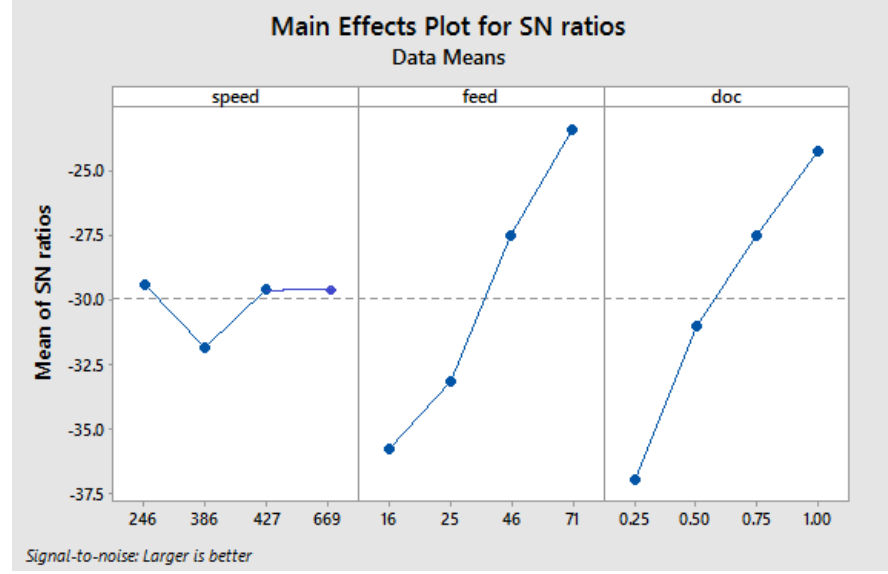

Figure 4: Main effect plot for the MRR

From the above analysis of both figures i.e., from main effect plots of $\mathrm{s} / \mathrm{n}$ ratios of both $\mathrm{Ra} \&$ Mrr ,it is clearly observed that N2,F1,D4 gives minimum surface roughness and N1,F4,D4 gives maximum material removal rate.

\section{CONCLUSIONS}

The effect of process parameters on surface roughness and material removal rate are analyzed through the results from milling of OHNS steel with Tungsten Carbide tool reveals the following conclusions.

- Taguchi is an efficient and systematical methodology for optimizing turning parameters and can be utilized rather than engineering judgment.

- It is observed that feed is the most influential controlling factor on surface roughness variation is feed followed by Depth of cut.

- The ANOVA reveals that the percentage contribution of feed (54.66\%) is the dominant parameter followed by Doc (26.85\%) for surface roughness

- It is observed that Feed is the most influential controlling factor on material removal rate is feed followed by Doc.

- The ANOVA reveals that the percentage contribution of Feed (54.45\%) is the dominant parameter followed by Doc (34.38\%) for material removal rate.

- It is concluded that N2,F1,D4 are the optimum conditions which gives better surface finish.

- It is also concluded that N1,F4,D4 are the optimum cutting conditions which gives maximum material removal rate.

\begin{tabular}{|c|c|c|}
\hline \multirow{2}{*}{$\begin{array}{c}\text { Ohns } \\
\text { steel }\end{array}$} & \multicolumn{2}{|c|}{ Taguchi } \\
\cline { 2 - 3 } & $\mathrm{Ra}$ & $\mathrm{Mrr}$ \\
\hline Speed & 386 & 246 \\
\hline Feed & 16 & 71 \\
\hline doc & 1 & 1 \\
\hline
\end{tabular}

Table 9 .The Optimum cutting conditions for process parameters. 


\section{REFERNCES}

[1] ANDSAHOO, P., BANDYOPADHYAY, A., ROUTARA, B.C., Roughness modeling and optimization in CNC face milling using response surface method: effect of work piece material variation, International Journal of Advance Manufacturing and Technology, Vol. 40, pp.1166-1180, 2009.

[2] BAJIC, D., LELE, B., AND ZIVKOVIC, D., Modeling of machined surface roughness and optimization of cutting parameters in face milling,

[3] BASKAR, N., KANNAN, S., Modeling and Optimization of Face Milling Operation Based on Response Surface Methodology and Genetic Algorithm, International Journal of Vol. 5, pp. 4164-4176, 2013.

[4] BAYRAMOGLU, M., OZCELIK, B., The statistical modeling of surface roughness in high speed flat face milling, Int J Mach Tools Manuf. 46: 1395-1402, 2006.

[5] CHANDRASEKARAN, K., MARIMUTHU, P., KANDMANIMARA, A., Machinability study on AISI 410 with different layered inserts in CNC turning during dry condition, International Journal of Engineering\& Material Science, Vol. 20, pp.398-404, 2013.

[6] CHANG,C.K., LU,H.S., Design optimization of cutting parameters for side milling operations with multiple performance characteristics, Int. J. Adv. Manuf. Technol. 32:18-26,2007.

[7] CHEN JC., LI CM., LOU MS., Surface roughness prediction technique for CNC face milling, J. Ind. Technol. 5(1):1-6, 1998.

[8] CHOCKALINGAM,P., WEE LEE HONG., Surface Roughness and Tool Wear Study on Milling of AISI 304 Stainless Steel Using Different Cooling Conditions, International Journal of Engineering and Technology Vol. 2, No. 8, pp.1386-1392, 2012.

[9] FUH, K.H., WU, C.F., A proposed statistical model for surface quality prediction in face-milling of $\mathrm{Al}$ alloy, Int $\mathrm{J}$ Mach Tools Manuf. 35: 1187-1200, 1995.

[10] JOSHI., AMIT\& KOTHIYAL., PRADEEP., Investigating effect of machining parameters of CNC milling on surface finish by taguchi method International Journal on Theoretical and Applied Research in Mechanical Engineering, Volume-2, Issue-2, pp. 113-119, 2013. 